\title{
Influence on the Shift the Product Precision of MAChining Process AND EligibiLity
}

\author{
Kateřina Bícová, Martin Melichar \\ University of West Bohemia, Univerzitní 8, Pilsen 306 14, Czech Republic
}

\begin{abstract}
The article discusses the significance degree of influence on the shift the product precision of machining process and eligibility. The aim is to detailed analysis whether the outputs of the morning and night shifts a statistically significant difference. In the automotive area are $80 \%$ of all manufacturing operations performed serially and in the framework of shift work. Inborn rhythm of humans can affect the entire production process. Because the weakest link of the production chain has an impact not only the eligibility of the manufacturing process, but also to the final product quality. To detailed analysis of the manufacturing process is used progressive methods of SPC and then determined the eligibility process. This ensures the identification of adverse effects, their correlation with the behavior of the production process and assembled average performance curve of each shifts.
\end{abstract}

Keywords: significance degree; precision; eligibility; SPC; shift; human factor; automotive; machining process
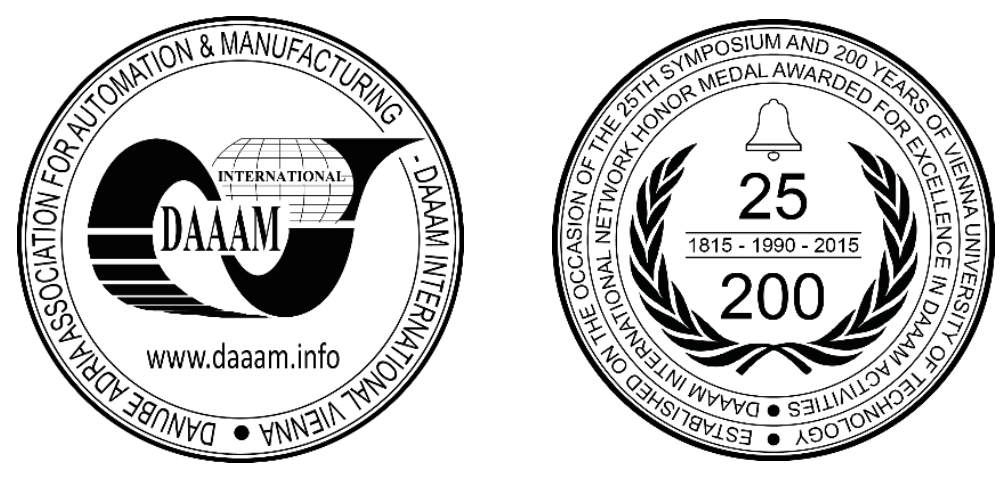

This Publication has to be referred as: Bicova, K[aterina] \& Melichar, M[artin] (2016). Influence on the Shift the Product Precision of Machining Process and Eligibility, Proceedings of the 26th DAAAM International Symposium, pp.0508-0512, B. Katalinic (Ed.), Published by DAAAM International, ISBN 978-3-902734-07-5, ISSN 1726-9679, Vienna, Austria

DOI: $10.2507 / 26$ th.daaam.proceedings.068 


\section{The introduction - present state}

Currently, every company belongs to the global economy, and if it wants to maintain its standards, must learn to be competitive in the global market. Therefore, it must all companies operating in the market to respond to rapidly changing customer demands, constant downward pressure on prices and increasing the quality of products and services. For ensuring rapid response is related to knowledge of their processes. The process is influenced by many factors. In this case, we focus on the human factor and the impact of the shift. In the automotive area, is already commonplace in total, there are $80 \%$ of all manufacturing operations performed serially, and that production is 24 hours. From which it follows that there is need to ensure employee on the night shift. Night shift with them but they carry a lot of difficulties.

The human nature is at work day and night to relax. Man in everyday life governed by the 24-hour rhythm, which is inborn and it is controlled by the biological clock. Therefore, it is not at all easy to adapt to shift work. This innate rhythm can affect the entire production process. Because the weakest link in the production chain has an impact not only on the ability of the manufacturing process, but also to the final product quality.

The biggest demand is night work. It's not just for reasons of decline in physiological performance, but often associates and insufficient rest after shift in the morning the next day. There are some differences between the maximum and minimum performance during the 24 hours are very large. Those doing work at night considerable difficulty and can be performed over a longer period of time without injury. Others have daily performance curve is relatively flat, and night work may be relatively well adapted to exercise it in the long term. Another factor is the occurrence of stress that can cause psychosomatic problems or reduce the ability to maintain vigilance and settlement operators with shift work. [3]

Based on the research resources available that solves the human factor influence on production precision, the research team was assembled. The research team studied morning and night shift workers themselves looking for other possible influences of human factor on production precision. All this is done with the experimental measurements in real conditions of the company. The basic idea is to minimize the impact of human factors. Because the human factor is an integral part of every activity in the company, therefore it is necessary to address this issue.

To eliminate the human factor measurement and control part is used measuring device Renishaw Equator. Why Renishaw Equator? When selecting, assessing and current possibilities of CMM on the market, any of them offer flexibility, used friendliness, performance measurement per unit of time. But only Equator has ability to work in automatic mode, for which the device is very well prepared. It devalues competitors in 3D measuring with the unique architecture, based on the parallel kinematics.[10]

This measuring device is (after changing sensor unit) also suitable for measuring very small parameters such a micro-geometry of cutting tools. It was, among others, successfully tested in laboratories at the University of West Bohemia in Pilsen. Measured parameters and experimental details are given in the article [11].

The aim of this paper is therefore detailed analysis whether the outputs of the morning and night shifts a statistically significant difference. A detailed analysis of the manufacturing process is used progressive methods of SPC and subsequently determined the eligibility process. This ensures identification of the adverse effects and their correlation with the behavior of the production process. Based on these results compiled average performance curve day.

\section{The product precision of machining process and eligibility}

The analysis of measurement data of a specific machine components which are used in the automotive field. Production of components made serially $24 \mathrm{hrs}$, therefore on 3 shifts. Production of precision components requires $100 \%$ control. For the control components is used universal 3D measuring device. The basic principle of the measurement process is based on a comparator comparing the measured and standard parts. Etalon is such a part that is made as a model for comparison. Relevant measurement data are now used more often and in many ways than ever before. Most of the conclusions of the manufacturing process, as adjusted, whether statistically mastered etc., Is just based on measured data. [1]

From each of the relevant data accumulated from control machine components. A very important step before the actual analysis is the data sorting. The purpose is to divide and organize the data according to one or more characters (aspects, features, criteria, etc.). It is important that the group have been designed to allow them to integrate the entire data file, and for each value must pay clearly which group the value included [6].

The data in this case are divided into 96 subgroups and after 15 elements. Each subgroup contains data measured during 15 minutes. The following Fig. 1 is a cut of the table with the calculated values for each subgroup.

For a detailed analysis of the production process is used by the method SPC. It is a tool with which to monitor long-term stability of the system, whether the studied process behaves as expected. It can judge whether the parameter variation caused by random fluctuations, or it is a special cause. Use is possible wherever the parameter is monitored successively over time. $[7,8]$

Control charts help explain the measurement results both in terms of dispersal process (variability), and in terms of its position (mean process). Therefore, control charts presented in pairs. The most common are diagrams of a pair $(\overline{\bar{X}}$ bar, R) diagrams. These values obtained by the sample mean values of the subgroups, which is a measure of the position of the process, and the range of values in each subgroup, a rate dispersion process. These diagrams are useful tools for measuring variations in process margin can be easily calculated and is hearty small range of subgroups. $[9,12]$ 


\begin{tabular}{|c|c|c|c|c|c|c|c|c|}
\hline \multicolumn{2}{|r|}{ time } & & $\mathrm{X}$ bar & 5 & 52 & $\min$ & $\max$ & $\mathbf{R}$ \\
\hline & $0: 00: 00$ & $0: 14: 59$ & $16,0021^{\top}$ & 0,00228 & $5,20952 \mathrm{E}-06^{\top}$ & $15,999^{\top}$ & 16,006 & 0,007 \\
\hline & $0: 15: 00$ & $0: 29: 59$ & $16,0014^{\top}$ & 0,00112 & $1,25714 \mathrm{E}-06^{\top}$ & $16^{V}$ & 16,004 & 0,004 \\
\hline & $0: 30: 00$ & $0: 44: 59$ & $16,0025^{\nabla}$ & 0,00272 & $7,40952 \mathrm{E}-06^{\mathbf{V}}$ & $15,998^{\top}$ & 16,009 & 0,011 \\
\hline & 0:45:00 & $0: 59: 59$ & $16,0033^{\top}$ & 0,00183 & $3,35238 \mathrm{E}-06^{\prime}$ & $16^{r}$ & 16,008 & 0,008 \\
\hline & 1:00:00 & $1: 14: 59$ & $16,003^{\top}$ & 0,0022 & $4,85714 \mathrm{E}-06^{\top}$ & $16^{V}$ & 16,007 & 0,007 \\
\hline & $1: 15: 00$ & $1: 29: 59$ & $16,0033^{\top}$ & 0,00194 & $3,78095 \mathrm{E}-06^{\prime}$ & $16,001^{\top}$ & 16,007 & 0,006 \\
\hline 7 & $1: 30: 00$ & $1: 44: 59$ & $16,0025^{V}$ & 0,00119 & $1,40952 \mathrm{E}-06^{\top}$ & $16^{V}$ & 16,005 & 0,005 \\
\hline & $A=$ & 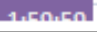 & $1<$ nnos & $n n n 10$ & O ICTIAC OCV & ${ }_{1 c^{\prime}}$ & $1 c \mathrm{Anc}$ & $n \cap n c$ \\
\hline
\end{tabular}

Fig. 1. Table with the calculated values for each subgroup

Firstly are determined the basic statistical characteristics necessary to construct control charts and determine the eligibility of process for the day. Fig. 2 shows an example diagram for mean and Fig. 3 for the range for the selected day.

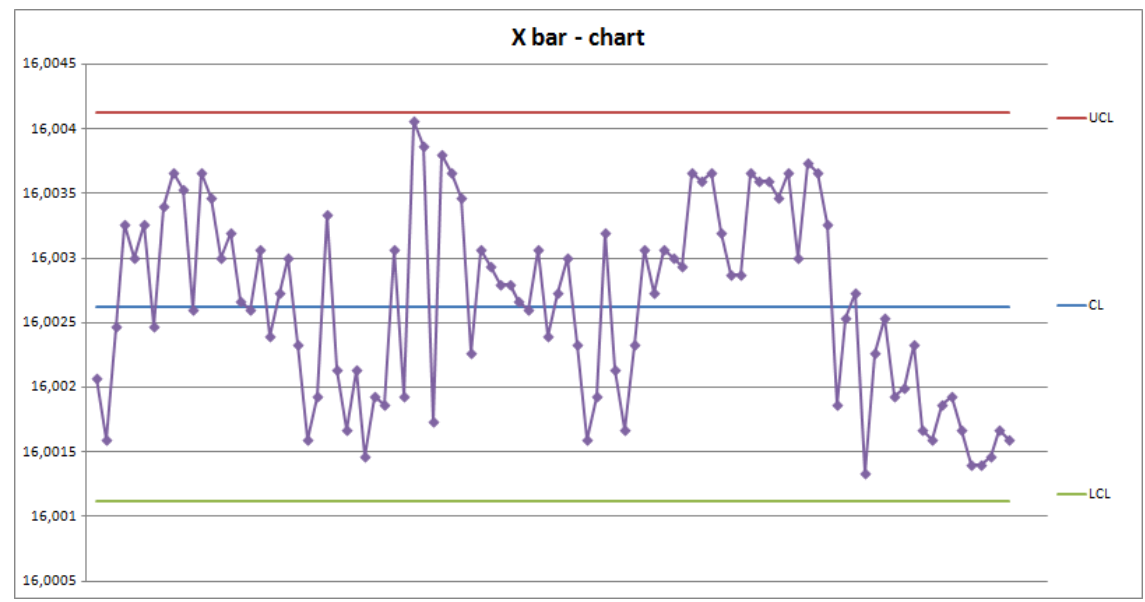

Fig. 2. Control chart for mean

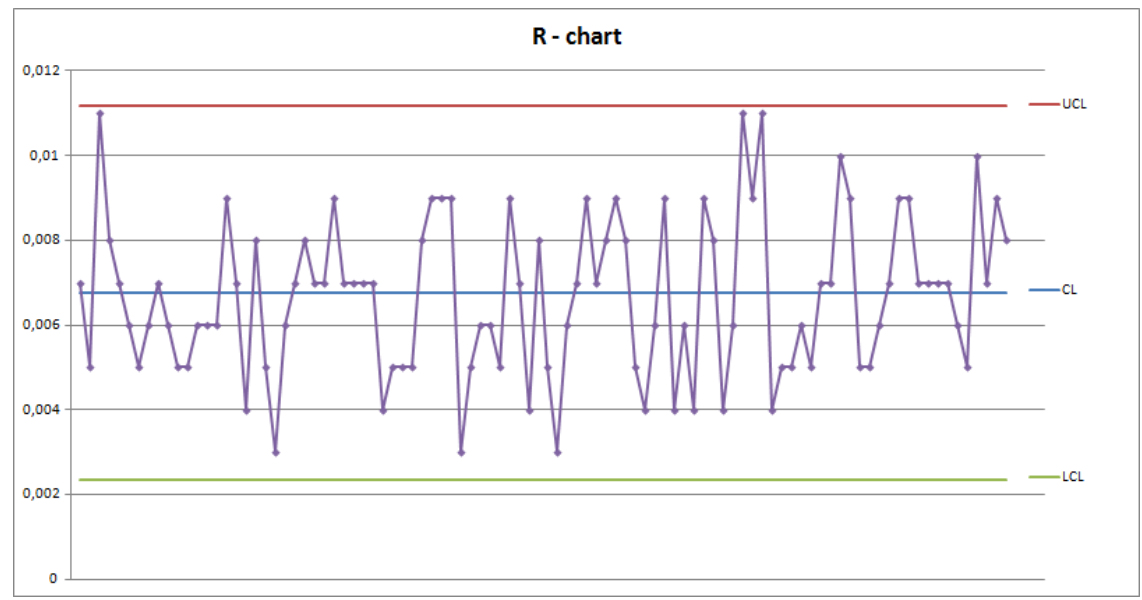

Fig. 3. Control chart for range

Although this is a very accurate production of critical components, it is obvious that the process without eliminable identifiable causes show considerable deviations.

\section{The performance curve}

When determining the degree of significance of the impact of the shift to the manufacturing accuracy of the machining process is in this case the emphasis on performance during the shift. It is believed that the performance of daytime uneven. Its fluctuations are influenced by the effects of daily biorhythms and emerging fatigue. After the initial phase of initial training, which is repeated after each interruption of work, the performance increases, then decreases due to fatigue. After resting the performance increase again, but then declines by the end of the work shift. On the working efficiency curves during a shift is also involved in emotional and volitional tension, which prevents a decrease in productivity especially when you set the start the onset of fatigue. [4] So the question is, what would be an objective 
measurement of the average full-day performance curve for high-precision manufacturing of machine components for the area automotive.

For each day of the performance curve is drawn. It is actually a curve pointing to the level of accuracy of production, differences in measurement values from the central value. Therefore depends on the ability of humans and machines involved in the manufacturing process. In this case, mainly the human factor which may affect the accuracy of manufacture. On the basis of the performance curves for each day they are calculated average values of performance for each hour and subsequently assembled average performance curve for the whole of the monitored period.

The following chart Fig. 4 shows the average performance curve of the day. According shifts a day can be divided into 3 parts, after 8 hours. In each section can be seen a significant drop in performance. In the first part, between midnight and eight o'clock, is the largest decrease in performance of around 5 o'clock in the morning. The second part is a big drop between 11 and 12 additional hours, when it is planned and in most cases the lunch break. The third part is a distinct decline in performance of around 20 o'clock in the evening.

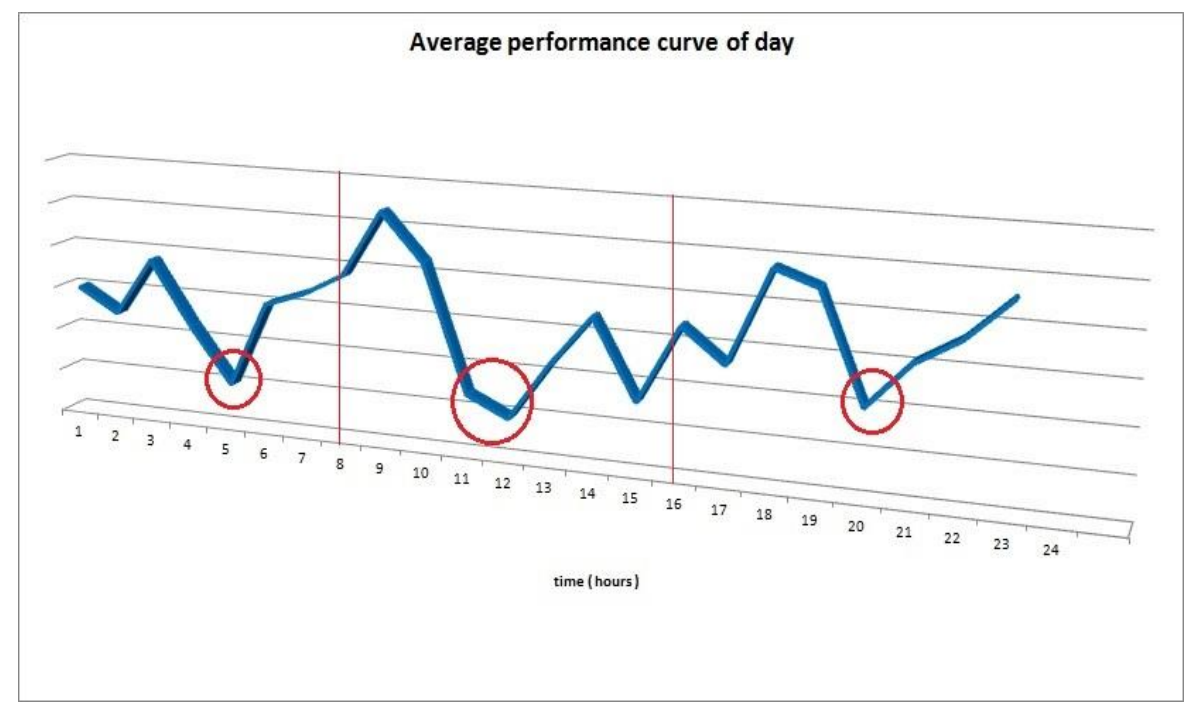

Fig. 4. The average performance curve of the day

The following chart Fig. 5 shows again the average performance of the curve, but the division into 3 parts after 8 hours is offset by the beginning of shifts in most businesses. Here, too, visible in every part of the significant decline in performance. In the first part between 6 and 14 hours is significant fall between 11 and 12 additional hours. The second part has a distinct drop in performance of about 15 and 20 o'clock in the evening. The third part is the biggest performance drop of around 5 o'clock in the morning.

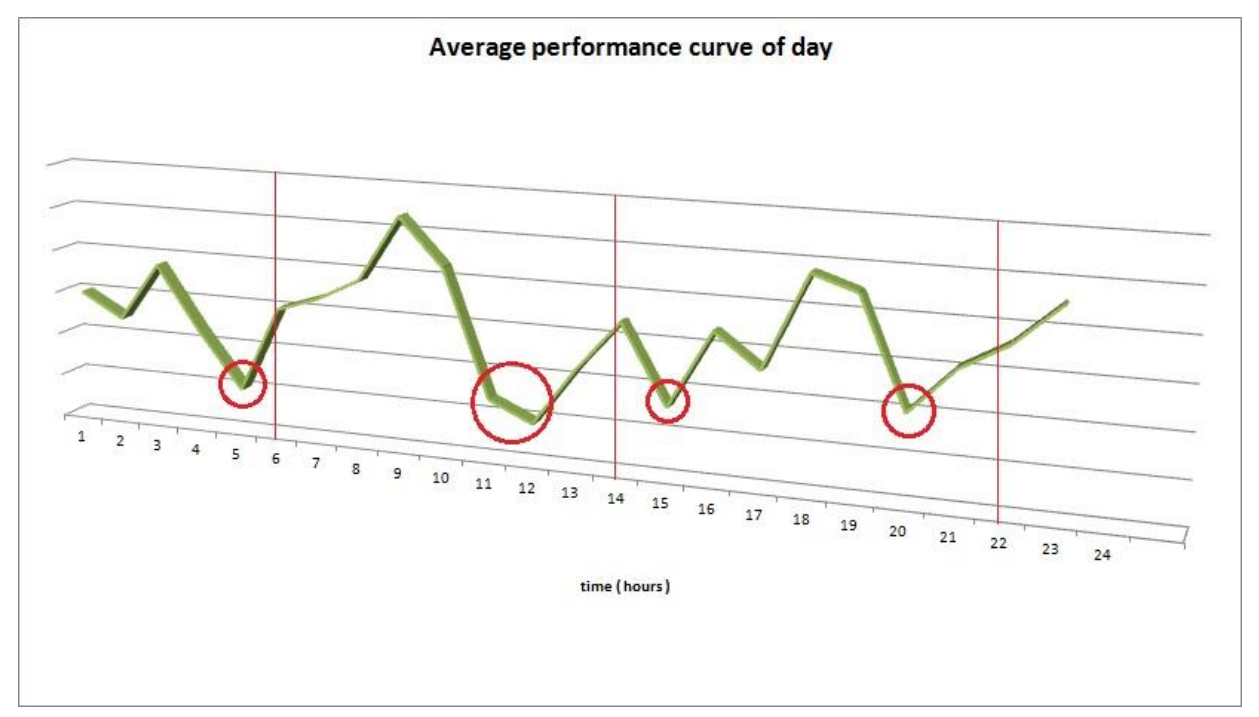

Fig. 5. The average performance curve of the day 
It can say that the two graphs clearly show that afternoon and night shifts show considerable variation in performance. From six o'clock in the morning performance increases significantly until about the ninth and tenth hour, when it reaches the maximum value of the day.

\section{Conclusion}

Very important and inseparable share in the entire production process are the people. Quality work in this area is very important. However, it is important to realize that quality work is not naturalness, but a consistent and high quality training, regular training and responsibility of each individual. The performance value of each person's is variable, dependent on many factors. There are not only significant individual differences between people, but the performance also changes throughout life and even during the week and every working day.

The research team, in this case focused on the monitoring of product precision of machining process with respect to the human factor. Long-term monitoring, it was found that the production precision of the machining process is greatly affected by human factors and performance in real conditions actually varies. After further are detailed analysis of the process was confirmed by the fact that the shift operation has on performance and therefore on the manufacturing precision machining process really influence.

As a complement to this analysis it can be said that also faults and any downtime are growing in the afternoon shift and night shift gradate. Causes an increase in failures and downtime are different - from obsolete machines, despite the lack of a maintenance man on the night shift, to the untrained machine operators on the night shift and the non-standard machine operation and possible damage. How does it work that contributes to the cause of the downtime is needed to analyze. [5]

Regarding the findings of the final curve, it is necessary that the company management was familiar with the situation. It can then provide eg. regular breaks to rest, after which the focus and efficiency increases again. When properly adjusted, the length of shifts and the rhythm of work should go to achieve a balanced all-day performance curve.

Due to limitations in this case, monitoring data collection was carried out only within weeks, which is a relatively short period of time. Therefore, it is already scheduled for long-term monitoring with regard to performance and precision manufacturing process. In addition to the significance degree of the influence of the shift also includes other properties that affect the relevance of the human factor.

Shift work is common in many occupations that directly affect the health and safety of others, whereas quality of life, health, and safety during shift work and the commute home can affect workers in any field. [2] The human factor has a significant share level precision manufacturing, it is a risk factor for which it is necessary to bear in mind when planning and management of machine production, especially in the automotive field, where precision and quality of production in the first place.

\section{Acknowledgements}

The present contribution has been prepared under project SGS031-2013 and project LO1502 'Development of the Regional Technological Institute under the auspices of the National Sustainability Program I of the Ministry of Education of the Czech Republic aimed to support research, experimental development and innovation.

\section{References}

[1] MSA (Measurement System Analysis) Praha : ČSJ, 2011. ISBN: 978-80-02-02323-5.

[2] Kenneth P. Wright Jr., Richard K. Boganb, James K. Wyatt : Shift work and the assessment and management of shift work disorder (SWD), Sleep Medicine Reviews, Volume 17, Issue 1, February 2013, Pages 41-54.

[3] V.M. Ognianova, D.L. Dalbokova, V. Stanchev : Stress states, alertness and individual differences under 12-hour shiftwork, International Journal of Industrial Ergonomics, Volume 21, Issues 3-4, March 1998, Pages $283-291$.

[4] Ergonomics: www.ped.muni.cz/wsedu/zdroj_mat/stud_mat/terminy/ergonomie.doc, cited: 27.8.2015.

[5] Efficient processes: http://www.efektivniprocesy.cz/vykonnost.html, cited: 26.8.2015.

[6] Meran, R., John, A., Roenpage, O., Staudter, Ch. Six Sigma + Lean Toolset (Mindset for Successful Implementation of Improvement Projects). Berlin : Springer, 2013. ISBN: 978-3-642-35881-4.

[7] Tabak, John. Probability and statistics: The science of uncertainty. New York : Fact On File, Inc., 2004. ISBN: 08160-4956-4.

[8] ČSN ISO 8258. Shewhartovy regulační diagramy. (Shewharts control charts) Praha : Český normalizační institut, 1998.

[9] Horálek, V. QS - 9000 SPC. Praha : ČSJ, 1999. ISBN: 80-02-01293-3.

[10] Martin Melichar, Dana Kubátová: Processing Data from Automatic Measurement Device, Procedia Engineering, Volume 100, 2015, Pages 899-906.

[11] J.Fulemova, Z.Janda, Influence of the cutting edge radius and the cutting edge preparation on tool life and cutting forces at inserts with wiper geometry, Procedia Engineering, 24th DAAAM International Symposium on Intelligent Manufacturing and Automation 2013, Volume 69, (2014), 565 - 573.

[12] Liviu Dorin Pop, Nagy Elod: Improving Product Quality by Implementing ISO / TS 16949, Procedia Technology, Volume 19, 2015, Pages 1004-1011. 